A s i a $\mathrm{n}$ J o u r n a l o f
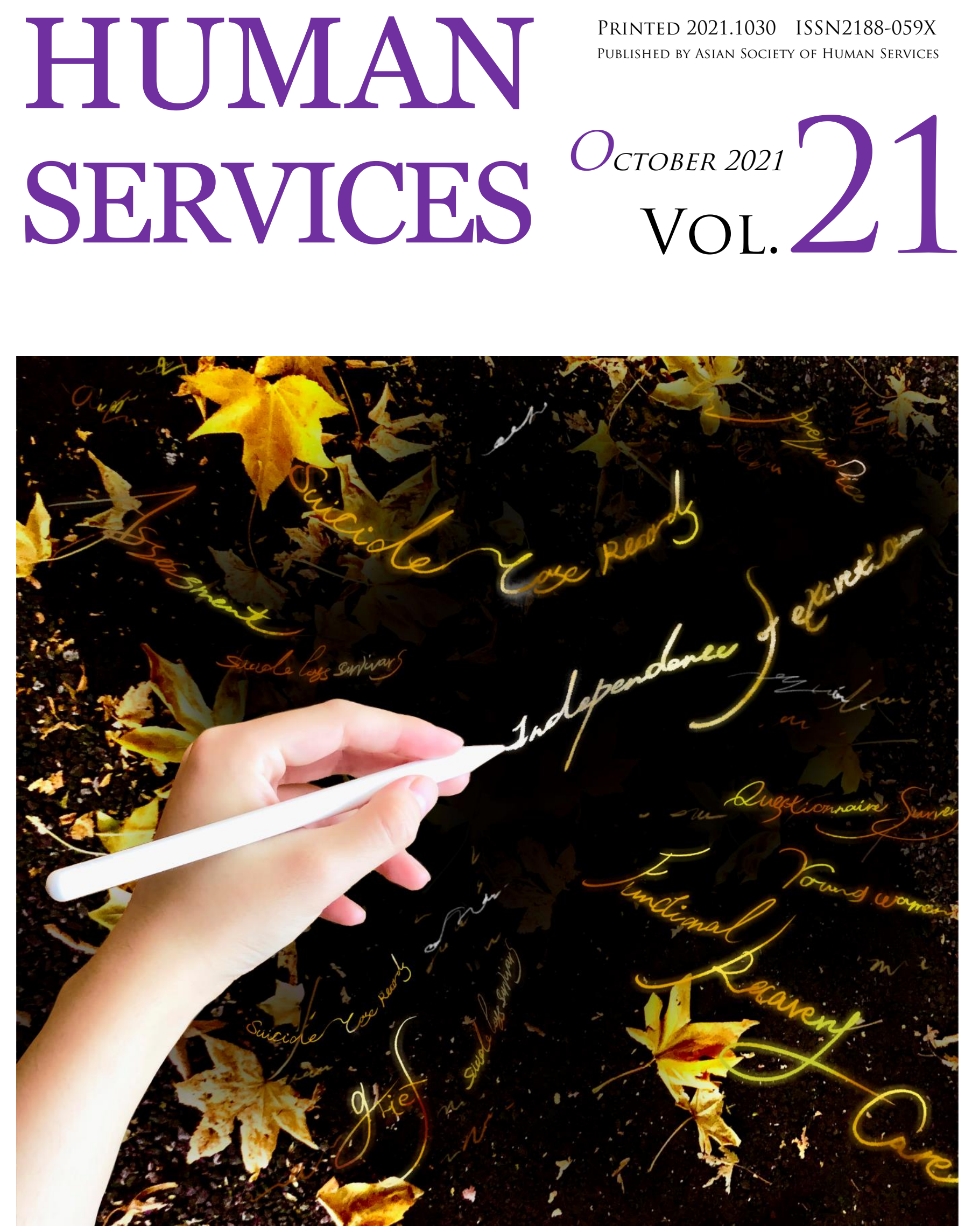
Short PAPER

\title{
Characteristics of Case Records and Staff Awareness in Institutions for Persons with Intellectual Disabilities
}

\author{
Toru SUZUKI 1) Kazuaki MAEBARA 1) \\ 1) Faculty of Education and Human Studies, Akita University, Japan
}

\begin{abstract}
This study aims to grasp the characteristics and trends of case records and staff awareness in institutions for persons with intellectual disabilities. The study analyzed the descriptive content of the case records of users with many problematic behaviors as well as those with fewer problematic behaviors in a certain residential facility. To this end, the study conducted a questionnaire survey on the staff regarding the case records. The results confirmed that the case records contained accounts of health status and daily routines, regardless of the user. However, users who reported serious problematic behaviors were significantly more likely to have accounts of individual episodes and problematic behavior. Furthermore, a considerable number of the staff felt burdened by the case records. Based on these findings, the study discusses the future directions for case records.
\end{abstract}

$<$ Key-words $>$

Institution for Persons with Intellectual Disabilities, Case Records, Questionnaire Survey

Received

July 28,2021

Revised

September 2, 2021

Accepted

September 6, 2021

Published

October 30, 2021 suzukirtoru@ed.akita-u.ac.jp (Toru SUZUKI; Japan) Asian J Human Services, 2021, 21:52-60. (C) 2021 Asian Society of Human Services 


\section{Introduction}

According to a survey by the Japanese Association on Intellectual Disability in 2019, $95 \%$ of people with intellectual disabilities - who were admitted to and used a facility were categorized under disability support classification $\geq 4$. Additionally, there were many users who exhibited strong tendencies towards harming themselves or others. ${ }^{1)}$ To address such problematic behaviors, efforts that emphasize raising staff qualifications to the level of skilled professionals have been carried out in the facilities. Specifically, it was pointed out that the problematic behavior of patients lessened when the staff applied support methods proposed by experts at third-party institutions. ${ }^{2)}$

However, the continuation of high quality support inside facilities has become an issue. ${ }^{3)}$ Many facilities operate in two shifts: a day shift and a night one. Thus, it is difficult to provide opportunities that create a shared understanding among the staff. ${ }^{4)}$ In other words, it is possible to enhance the common understanding among the staff and provide ongoing services by sharing information about the facility's users. However, this may result in transitory improvements, regardless of the positive measures adopted, unless proper attention is given to the information provided to the staff, their workload, and so on. Considering this, records about the daily users (hereinafter, case records) may be the most effective tool for creating a common understanding among the staff. In addition, case records can also serve as valuable information about users and changes in their condition over time. However, at present, the contents of the case record forms are entrusted to each facility, and to date, a detailed examination of these contents has not been done. In facilities shared by users with disorders of varying degrees, it is essential to consider the future support methods by the staff, the information shared on the case records, and the awareness of the staff about these records.

Therefore, the present study aims to analyze the descriptions in case records and its contents. The study's subject is a facility admitting persons with intellectual disabilities. In addition, this study aims to create an awareness survey for the staff and clarify the characteristics of the case records and staff awareness.

\section{Subjects and Methods}

\section{Target Facilities}

The authors received study cooperation from Facility $\mathrm{C}$ operated by corporation B in prefecture A. Facility $\mathrm{C}$ is a large-scale utility that provides assisted living services and engages in daily and local activities, short-term admissions, after-school day services, consultation and support, as well as group living assistance. The facility also offers assistance in entering the facility. Facility $\mathrm{C}$ comprises four dormitory buildings, two each for men and women, with support staff of the same gender as the users of each dormitory. 
The daily routine is somewhat like this. After waking up, the users get dressed and eat breakfast in the dining room. Next, after brushing their teeth, they participate in a morning meeting (a health check-up) and engage in radio calisthenics, after which they participate in group activities. In the afternoon, they bathe or clean their rooms after lunch. After the evening meeting (health check-up) is finished, they have dinner and enjoy some leisure time before going to bed. Toilet assistance is provided for the users who need it during the breaks between activities. On weekends and holidays, group activities and bathing are considered leisure activities, while for the remainder of the day, the weekday schedule is followed. Events like birthdays and Christmas parties are also held.

In this study, we focused on one men's dormitory (25 users, 13 staff) and one women's dormitory (20 users, 12 staff). The average age of users in the men's dormitory was 33.3 years (the youngest and oldest users were 23 and 47 years old, respectively). Of these users, 25 suffered from intellectual disabilities (five among them had overlapping physical disabilities) with an average disability support classification of 5.5. The average age of users in the women's dormitory was 41.2 years (the youngest and the oldest users were 23 and 59 years old, respectively). Twenty women had intellectual disabilities (five among them also had overlapping physical disabilities) with an average disability support classification of 5.5 .

\section{Case records of users}

The two-shift work system in Facility C consisted of a day shift (of 6 staff members) and a night shift (1 staff member). The staff members maintained the cords of the entire building, including the case records for each user, until their duty hours were over. As the description method of the case records, they added a title to the header and noted the circumstances at the site under the title. To avoid bias in the targets, we made the staff members select four users - one male and one female user, each with serious problematic behaviors in communicative and intellectual ability, and another pair of male and female users with relatively minor problematic behavior. In this study, self-harm and aggression were defined as problematic behaviors, and users with a high frequency of such behaviors were designated as "users with serious problematic behavior" and users with a low frequency were designated as "users with minor problematic behavior." The case records of the four users (over a 12-month period, from April 2018 to March 2019) were used.

Case records were classified based on the KJ method. 5) The KJ method is a method of qualitative data analysis. It is a way of interpreting data by recording them on cards and grouping them based on what can be read from them. The case records were classified into six items, namely (1) health status (vital signs, status of hospital visits, condition of injuries, allowance, drug compliance), (2) daily routine (intake of meals, participation in group activities, participation in events, bathing, defecation), (3) problematic behavior (annoying behavior like making strange noises, destructive behavior like damaging utensils, acts of self-harm like repeatedly banging one's head against a wall, acts of 
harming others like biting, etc., trouble with other users), (4) individual episodes (interactions with the staff and other users), (5) contact from the family (return home, supply of clothing and food), and (6) matters for handover (change of clothes and mail). Next, their numbers were counted. For the reliability assessment of the classification, we requested a classification of the four case records from a third party and calculated the kappa coefficient. Consequently, it exhibited good consistency at $\kappa=0.82$. If no consistency was observed, those cases records were reclassified based on consultations.

\section{Staff awareness}

An awareness survey about the case records was undertaken for the staff working in the two dormitories. In June 2019, a questionnaire sheet was distributed to 20 staff members (10 each in the men's and women's dormitories) who had been working continuously in the two buildings in the preceding business year, and their anonymous responses were solicited. Responses were received from 14 staff members (6 male and 8 female; a response rate of $70 \%$ ), and these were used for our analysis (there were no missing entries).

On the questionnaire sheets, the respondent staff members were first asked about the time required for completing the case reports and the feeling of burden created by these. The respondents had to enter the amount of time required, and they had to choose one of four responses to answer if they felt burdened (I feel it; I feel it somewhat; I do not feel it much; I do not feel it at all). In addition, they had to freely describe general matters requiring attention in the case records and matters requiring attention while describing users with severe and minor problematic behaviors, respectively. Finally, the respondents were also asked to describe the items requested for the case records.

The response descriptions were categorized using the KJ method, and the tendencies of these contents were organized. 5)

\section{Ethical concerns}

The purpose of the study and the survey method was explained to corporation B as well as the facility's users and their families. In addition, it was explained that the facility and the individuals would not be identified, data would be strictly controlled, and the study's results would only be used for scholarly purposes. Finally, consent from these parties was obtained in writing. 


\section{Results}

\section{The men's dormitory case records (Figure 1)}

A total of 77,862 characters were devoted to users with serious problematic behaviors. There were 746 entries for the contents described, which were categorized as follows: (1) health status $154(20.6 \%)$, (2) daily schedule 296 (39.7\%), (3) problematic behavior 108 (14.5\%), (4) individual episodes $87(11.7 \%)$, (5) contact from family $47(6.3 \%)$, and (6) handover matters $54(7.2 \%)$.

A total of 57,257 characters were devoted to users with minor problematic behaviors. There were 715 entries for the contents described, which were categorized as follows: (1) health status 185 (25.9\%), (2) daily schedule 350 (49.0\%), (3) problematic behavior 17 (2.4\%), (4) individual episodes 1 (0.1\%), (5) contact from family 115 (16.1\%), and (6) handover matters $47(6.6 \%)$.
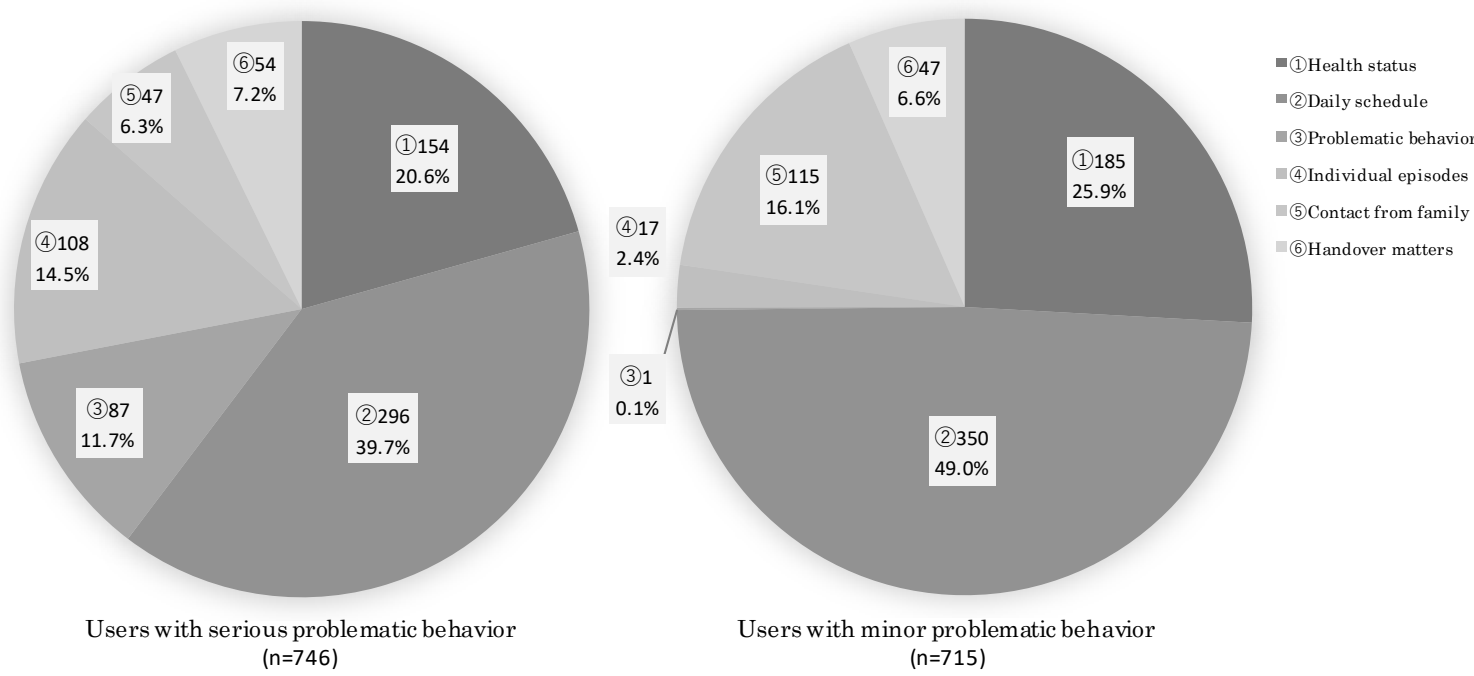

$<$ Figure 1 $>$ Summary of the case records of the men's dormitory

\section{The women's dormitory case records (Figure 2)}

A total of 146,058 characters were devoted to users with serious problematic behavior. There was a total of 962 entries, with a breakdown by category as follows: (1) health status $167(17.4 \%)$, (2) daily schedule 335 (34.8\%), (3) problematic behavior $153(15.9 \%)$, (4) individual episodes 201 (20.9\%), (5) contact from family 33 (3.4\%), and (6) handover matters $73(7.6 \%)$.

A total of 57,244 characters were devoted to users with minor problematic behavior. There were 544 entries, categorized as: (1) health status 123 (22.6\%), (2) daily schedule 229 (42.1\%), (3) problematic behavior $9(1.7 \%)$, (4) individual episodes $79(14.5 \%)$, (5) contact from family $43(7.9 \%)$, and (6) handover matters 61 (11.2\%). 

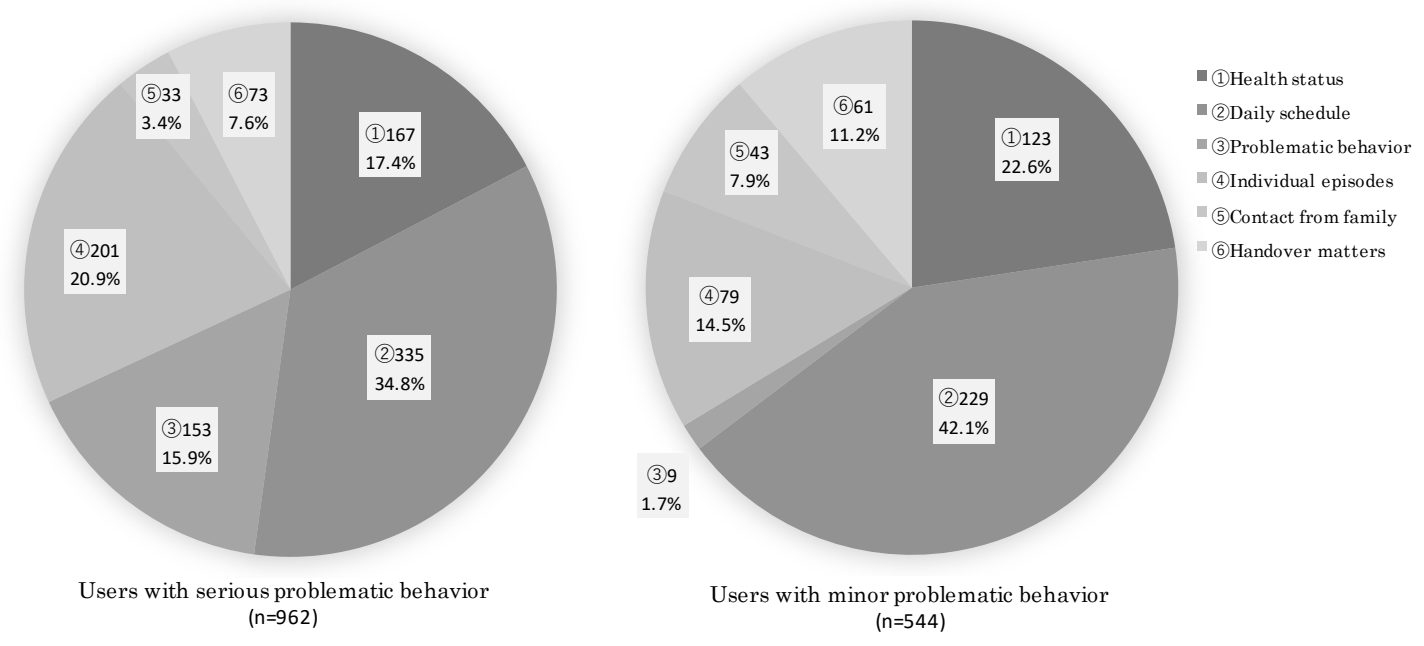

$<$ Figure 2> Summary of the case records of the women's dormitory

\section{Staff awareness about case records}

An average of 2.6 hours was required to complete case records (minimum 1 hour, maximum 4 hours). Regarding the responses to the feeling of burden, 4 staff members said they felt it, 7 felt it somewhat, 3 did not feel it much, and no one reported not feeling burdened at all.

For general matters requiring attention $(n=20)$, the responses were summarized under the following four categories: support contents in line with the individual support plan (n $=7)$, language use $(n=6)$, accurate description of the users' appearance $(n=6)$, and finding time to attend to the case records $(n=1)$. Not speaking colloquially as cited under language use.

Regarding matters requiring attention $(n=18)$ for users with serious problematic behavior, the responses were summarized under the following categories: describing the users' appearance other than problematic behavior $(n=9)$, detailed description of the problematic behavior $(n=7)$, and awareness of the staff $(n=2)$. In addition, the necessity of describing the user's ordinary appearance (since there is a tendency to describe only problematic behavior) was noted, while describing their appearance other than the problematic behavior.

The responses for the matters requiring attention $(n=16)$ for users with minor problematic behavior were summarized under the following categories: considering the need to consciously observe $(n=9)$, detailed description $(n=4)$, and avoiding repetition when describing the contents $(n=3)$.

The information required from the case records were summarized under the following five categories: a user's detailed appearance $(n=10)$, physical condition $(n=7)$, the user's new aspects $(n=4)$, staff awareness $(n=4)$, and handover matters $(n=1)$. Regarding staff awareness, it was opined that a staff member should also share the appearance of a user, 
about whom the staff member was personally concerned.

Table 1 shows the matters requiring attention in the case records.

< Table 1> Matters Requiring Attention in Case Records

\begin{tabular}{|c|c|c|c|c|}
\hline Item & Records in general $(n=20)$ & $\begin{array}{l}\text { Users with serious problematic } \\
\text { behavior } \\
(\mathrm{n}=18)\end{array}$ & $\begin{array}{l}\text { Users with minor problematic } \\
\text { behavior } \\
(\mathrm{n}=16)\end{array}$ & $\begin{array}{l}\text { Things required from the case } \\
\text { records } \\
(\mathrm{n}=26)\end{array}$ \\
\hline Contents & $\begin{array}{l}\text { Support contents in line with } \\
\text { the individual support plan (7) } \\
\text { Language use (6) } \\
\text { Accurate description of } \\
\text { appearance (6) } \\
\text { Finding the time to attend to } \\
\text { the case records (1) }\end{array}$ & $\begin{array}{l}\text { Description of appearance } \\
\text { other than problematic } \\
\text { behavior (9) } \\
\text { Detailed description of } \\
\text { problematic behavior ( } 7) \\
\text { Staff Awareness (2) }\end{array}$ & $\begin{array}{l}\text { Considering the need to } \\
\text { consciously observe (9) } \\
\text { Avoiding repetition while } \\
\text { recording contents (3) } \\
\text { Detailed description (4) }\end{array}$ & $\begin{array}{l}\text { Detailed appearance of the } \\
\text { user (10) } \\
\text { Physical condition (7) } \\
\text { New aspects of a user (4) } \\
\text { Staff awareness (4) } \\
\text { Handover matters (1) }\end{array}$ \\
\hline
\end{tabular}

\section{Discussion}

The study aimed to understand the characteristics of the case records in institutions for persons with intellectual disabilities. We now focus on a discussion based on the results.

The users' health status accounted for about $20 \%$ and the daily schedule for about $40 \%$ of the contents of the case records for both dormitories. Physical condition ranked number one among the matters required from the case records by the staff. Given the above, we can conclude that the case records are being applied as a tool by the staff to grasp the users' health status and their daily routine. In addition, language use is cited as a matter requiring attention in the general case records. Notably, none of the staff members responded with "did not feel at all," regarding the feeling of burden related to the case records. Although the case records are being prepared based on the individual support plan at Facility C, no strict rules have been established, and the matter to be described has been left to the discretion of each staff member. Thus, staff members may feel a great sense of burden about what and how they should describe the matters.

In both dormitories, the number of characters used in the case records to describe users with serious problematic behavior was greater than that used to describe those with minor problematic behavior. In addition, problematic behaviors and individual episodes were appropriately described. Considering this, although the case records serve as a tool for the staff to understand problematic behavior and share information, they may feel burdened about writing the records of users who show a high level of problematic behavior. However, the matters requiring attention in the case records included the need to describe appearance other than problematic behavior, for users with serious problematic behavior, as well as to consciously observe users with minor problematic behavior. Thus, the feeling of burden among the staff may have increased because they needed to write the case records by understanding the users from multiple viewpoints.

Awareness of the staff and new aspects of a user were mentioned as the information that the staff required from the case records. What the staff members notice or feel while 
engaging with the users is ultimately based on subjectivity, and we may not be able to conclude that this is suitable for case records describing only the facts. However, if we assume that problematic behavior occurs in a context wherein individual and environmental factors are intertwined, the incongruity or the expectations felt by staff members can serve as important clues for undertaking or revising support, and they should be shared among the staff. Creating a situation where the staff members can easily describe the users' appearance by providing them with entry examples may be possible. However, a variation may arise in the way in which the staff copes with this, if a framework is established.6) It may be important to conduct a study about the strategy to stay updated about what the staff notice or feel.

This study revealed two points: (1) although case recording has been an important tool to understand the condition of the users, many staff members feel burdened by case records; (2) case records are indispensable for sharing information among staff members, and we need to consider what should be recorded and how to reduce the burden on the staff in the future. In a survey about the actual state of work in a special nursing home for the aged, it has been suggested that the nature of work differs between the day and night shifts. In addition, there is a difference in the time required for dealing with the same tasks.7) In the current study, we have not focused on the effect of the difference between day and night shifts on case records or the staff's feeling of burden, and further study about this issue is likely needed. Moreover, in this study we limited our examination to a single facility. Furthermore, the format of the records and the time required to complete these as well as the staff's feeling of being burdened may vary depending on the facility. Owing to this, the present authors plan to conduct a large-scale study in the future to verify the validity of the study's findings. 


\section{References}

1) Japanese Association on Intellectual Disability. Annual Nationwide Report on the Facilities for Persons with Intellectual Disabilities. 2019, Japanese Association on Intellectual Disability.

2) Kuramitsu A \& Sonoyama S. Increasing task engagement in an adult with autism in a residential facility: Effectiveness of intervention based on functional behavior assessment and collaboration between facility staff and related services professionals. Japanese journal of psychology for human services, 2009, 5, 1-11.

3) Tomita M \& Muramoto J. Comprehensive support provided in a residential care institution to an autistic adult with aggressive behavior. Japanese journal of special education, 2013, 51, 301-310.

4) Tsuru K \& Usuda T. Study on the Consciousness of staff to the living environment in welfare facilities: Focus on the residential facilities for persons with severe intellectual disabilities. Journal of Life Culture, 2017, 54, 15-26.

5) Yamaura H. Shitsuteki-Togoho-Nyumon (in Japanese). 2012, Igaku-Shoin Ltd Publishing, Tokyo.

6) Teshima M. The way to the making of information sheets for staffs in a institution. Bulletin of the Faculty of Social Welfare, Yamaguchi Prefectural University, 2011, 17, 79-85.

7) Kuriki T, Sato Y, Nishiura I \& Matsubara H. Survey of task and burden of care workers in the special nursing home for the aged. Human welfare review, Den-en Chofu University, 2003, 6, 101-119. 


\title{
ASIAN JOURNAL OF HUMAN SERVICES EDITORIAL BOARD
}

\author{
EDITOR-IN-CHIEF \\ Masahiro KOHZUKI Tohoku University (Japan) \\ EXECTIVE EDITORS \\ LEE, In Jae Hanshin Univerisity (Korea) \\ Satoru EBIHARA Toho University (Japan)
}

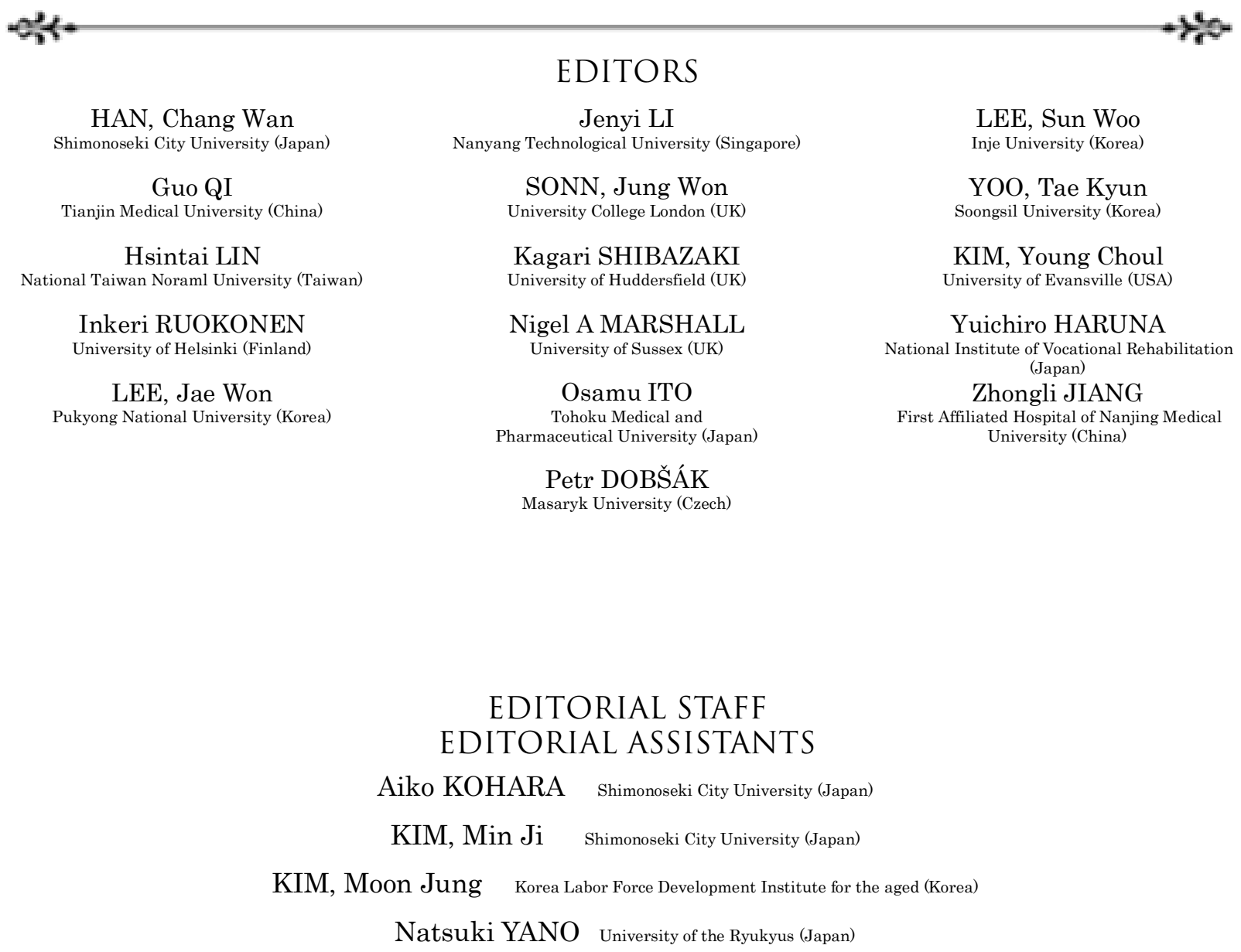

\footnotetext{
ASIAN JOURNAL OF HUMAN SERVICES

VOL.21 OCTOBER 2021

(C) 2021 Asian Society of Human Services
Presidents | Masahiro KOHZUKI \& LEE, Sun Woo
\#1Floor Ohara Bill, 2-11-5, Takezaki-Town, Shimonoseki-City, Yamaguchi-Prefecture, 750-0025, Japan E-mail: ashs201091@gmail.com
Production Asian Society of Human Services Press \#1Floor Ohara Bill, 2-11-5, Takezaki-Town, Shimonoseki-City, Yamaguchi-Prefecture, 750-0025, Japan E-mail: ashs201091@gmail.com

Publisher Asian Society of Human Services
} 


\section{ASIAN JOURNAL OF HUMAN \\ SERVICES VOL.21 OCTOBER 2021 \\ CONTENTS}

\section{ORIGINAL ARTICLES}

Factors Promoting Independent Excretion in Residents of Special Nursing Homes for the Elderly

Imagined Intergroup Contact Reduces Prejudice Against Suicide Loss Survivors;

An Empirical Study with Japanese Undergraduates

Akira YAMANAKA et al. p.18

Preschool and Kindergarten Teachers' Assessments of Children with Special

Needs and Influences on Their Assessments

Yijie LIU et al. p.29

The Verification of the Reliability and Construct Validity of the Disability

Awareness Program (DAP) scale:

Analysis of Cross-sectional Data and Longitudinal Data

Mamiko OTA et al. p.42

\section{SHORT PAPER}

Characteristics of Case Records and Staff Awareness in Institutions for Persons with Intellectual Disabilities

Toru SUZUKI et al. p.52

\section{REVIEW ARTICLES}

Effects of Physical Exercise on Mental Health of Frail Older Adults;

A Literature Review

Chaeyoon CHO p.61

Conceptual Analysis of Menstrual Disorders in Young Women

Eriko YAMAMOTO et al. p.73

Factors Affecting the Sense of Life Worth Living and Cognitive Function for Older Caregiver;

Current Situation and Issue based on Literature Considerations 